\title{
Aplicação de Game Design na Refatoração de um Jogo com Foco no Pensamento Computacional
}

\author{
Mauro M. Mattos, Luciana P. de Araújo Kohler, Fabrícia Diurex Zucco, Andrea Wuo, Bruno F. F. \\ Santos, Joan T., Leonardo Fronza, Heitor Ugarte, Gian Carlo Giovanella, Liz Rios Largura, Jéssica \\ Maria de Melo, Luma Kühl, Rafaele Caroline Wessling \\ Departamento de Sistemas e Computação \\ Universidade Regional de Blumenau \\ Blumenau, SC, Brasil \\ \{mattos, lpa, fabricia, awuo, bffsantos, lfronza, hucsilveira, gcgiovanella,lrlargura, jmmelo, lkuhl, rwessling\}@furb.br
}

\begin{abstract}
RESUMO
O Pensamento Computacional diz respeito a habilidade de resolver problemas, desenhar sistemas e compreender o comportamento humano com base em conceitos da Ciência da Computação. Dentro desse contexto, desenvolveu-se uma plataforma para o ensino do Pensamento Computacional para crianças de ensino fundamental, anos iniciais, com características de gamificação, denominada Furbot. Acontece que, a partir de estudos práticos com a plataforma, viu-se que a mesma não atrai tanto as crianças quanto os propriamente ditos jogos de computador. Dessa forma, foi realizado uma interação por meio do game design para a refatoração da plataforma afim de torná-la um jogo atraente para o público alvo, sendo que não perca suas características de ensinar o pensamento computacional. O game design ocorreu com a participação da equipe de desenvolvimento e de desenho durante 2 meses tendo como resultado um documento denominado game design treatment que contempla todas as características que o novo jogo deve assumir, bem como a formalização dos personagens e suas jogabilidades.
\end{abstract}

\section{PALAVRAS-CHAVE}

game design, pensamento computacional, game treatment.

\section{DESCRIÇÃO DO PROBLEMA}

Segundo Brackmann [1] "O Pensamento Computacional é uma distinta capacidade criativa, crítica e estratégica humana de saber utilizar os fundamentos da Computação nas mais diversas áreas do conhecimento, com a finalidade de identificar e resolver problemas colaborativamente através de passos claros de tal forma que uma pessoa ou uma máquina possam executá-los

\footnotetext{
Permission to reproduce or distribute, in whole or in part, material extracted from this work, verbatim, adapted or remixed, as well as the creation or production from the content of such work, is granted without fee for non-commercial use, provided that the original work is properly credited.

IHC 2019 - IHC NA PRÁTICA, Outubro 2125, 2019, Vitória, Brasil. In Anais Estendidos do XVIII Simpósio Brasileiro sobre Fatores Humanos em Sistemas Computacionais. Porto Alegre: SBC.

(C) 2019 by the author(s), in accordance with the terms of the Creative Commons Attribution-NonCommercial 4.0 International Public I icense (CC. BY-NC 4.0).
}

eficazmente". Nesse contexto, adaptou-se um framework denominado Furbot para uma plataforma em forma de um jogo para introduzir conceitos do Pensamento Computacional para crianças de ensino fundamental, anos iniciais.

A plataforma Furbot foi utilizada em oficinas com crianças de 07 a 11 anos durante os anos de 2017 e 2018, sendo que ao longo desses dois anos sofreu adaptações conforme as práticas eram realizadas [2]. As oficinas ocorreriam semanalmente ou quinzenalmente, de acordo com o grupo a ser trabalhado, durante uma hora, na qual as crianças praticavam a programação por meio da plataforma, solucionando os desafios apresentados [2]. Como critério de gamificação, a plataforma possui níveis de dificuldade, sendo que cada nível possui várias fases com missões a serem resolvidas. Ainda, conforme a resolução, o jogador recebe pontos que são acumulados e apresentados ao completar cada missão.

Acontece que, após os dois anos de experimentação em campo, percebeu-se que os jogos de vídeo game e de computador atraem mais as crianças do que jogos com objetivos pedagógicos, como o caso da plataforma que introduz o pensamento computacional. Deste modo, tem-se o desafio de transformar a plataforma atual do Furbot em um jogo atrativo para o público alvo de forma que não perca suas características de ensinoaprendizagem, mas que receba mais características relacionadas à gamificação e a jogabilidade relacionado a jogos de computador.

As seguintes seções descrevem a abordagem adotada para a aplicação do método, bem como os resultados alcançados. Por fim, são realizadas reflexões a respeito da aplicação e conclui-se o artigo.

\section{ABORDAGEM ADOTADA}

Para a realização do design da nova interface do Furbot, aplicou-se técnicas do game design. Segundo Adams e Rollings [3], a principal função do game design é definir o modo que um jogo funciona, descrevendo seus elementos e informações para a equipe que desenvolverá o jogo.

Para a realização do game design utilizou-se a metodologia indicada por Adams e Rollings [3] que é centrada no jogador. Essa metodologia define que o designer cria um jogador imaginário e responde questões relacionadas ao design do jogo 
como se fosse esse jogador. Os autores afirmam que nessa abordagem é importante que quem está projetando o jogo realmente pense como o jogador que jogará o jogo, levantando os aspectos que gostaria de utilizar durante seu entretenimento.

A metodologia foi aplicada junto a equipe de desenvolvimento e de design, no qual cada membro se colocou no lugar do jogador, visto que todos os presentes acompanharam as crianças utilizando a versão anterior da plataforma, sabendo de suas carências e anseios. Antes de iniciar as reuniões de game design cada participante esboçou suas ideias a partir de um jogador imaginário, informando seu perfil como jogador e quais funcionalidades o jogo não poderia deixar de fornecer. Além disso, indicou-se como esperava-se a aparência do jogo.

Seguindo o processo do game design ocorreram reuniões durante aproximadamente duas semanas para a concepção do novo jogo baseado na plataforma anterior, a elaboração do projeto e o detalhamento do mesmo. A partir das ideias esboçadas anteriormente por cada membro da equipe, pode-se guiar com maior facilidade as reuniões, de modo que as informações de cada um eram compartilhadas e discutidas com a equipe.

Para guiar cada uma das etapas, utilizou-se um modelo de High Concept e Game Treatment. O High Concept do jogo é o documento que descreve de forma breve conceitos importantes do jogo como: motivação do jogo, gênero, tipo de licença, forma de competição, pontos, requisitos de hardware e objetivos do jogo [4]. Já o Game Treatment define de forma mais específica conceitos do design do jogo, como: narrativa, personagens, história, gatilhos, jogabilidade, entre outros aspectos [5].

\section{RESULTADOS}

Após as duas semanas de reunião com toda a equipe envolvida, obteve-se uma concepção a respeito de como será a nova plataforma a ser desenvolvida. Decidiu-se que ela terá a mesma representatividade do Furbot em relação aos seus personagens principais e comandos de programação a serem utilizados, porém, entre uma fase e outra terão mini jogos que não se referem ao aprendizado da programação, sendo uma distração para o jogador.

Como gênero, optou-se por criar um jogo de aventura e ficção em 2D, linear e sequencial, baseado em níveis. Além do tema aventureiro, o intuito disto é o ensino do pensamento computacional, lógica de programação e conhecimentos gerais de maneira imperceptível.

Ainda, o jogo passou a ter um enredo resultante das reuniões de game design, bem como a ter novos personagens. Toda a jogabilidade foi definida, assim como a forma de pontuação e outras features necessárias para um jogo ser divertido e atraente.

De forma geral, após a finalização das reuniões, obteve-se como resultado os documentos do high concept e game treatment ${ }^{l}$ que servirão de fundamento para o desenvolvimento da nova plataforma do Furbot. Graças a estruturação desses documentos e da aplicação do game design pode-se estruturar todas as características essenciais de um jogo, conforme mencionado anteriormente. Ainda, a aplicação das técnicas fez com que a equipe pode tomar decisões a respeito do que espera do jogo, ao invés de receber um conceito pronto a ser desenvolvido.

\section{REFLEXÃO}

A partir da abordagem utilizada para a definição da nova versão do jogo, percebeu-se que o uso dos métodos e dos documentos fez com que a equipe de desenvolvimento e design pensasse como jogador da plataforma, permitindo assim com que funcionalidades mais atrativas fossem projetadas.

Por meio da estruturação dos documentos de high concept e game treatment foi mais fácil guiar o time para realizar os questionamentos e reflexões necessárias para a concepção do jogo. Algumas das questões não seriam pensadas caso não existisse esse modelo, fazendo com que talvez, no futuro, a informação aparecesse e boa parte do design tivesse que ser alterada novamente.

\section{CONCLUSÃO}

A partir da aplicação dos conceitos e técnicas de Game Design e dos modelos de high concept e game treatment obteve-se as novas definições da plataforma Furbot, buscando maior jogabilidade e atratividade para as crianças que a jogarão.

Por meio desses documentos, pode-se obter uma definição clara de como será o jogo, além da definição a respeito dos personagens e seus respectivos comportamentos. $\mathrm{O}$ enredo produzido, bem como essas características levantadas, permitirá que a equipe de desenvolvimento consiga estruturar o desenvolvimento do jogo de modo a disponibilizar módulos ou fases jogáveis por etapas. Ainda, para a equipe de design, ficará mais fácil o desenho e projeção dos personagens e dos cenários do jogo, pois por trás dos mesmos há a definição de comportamento e a própria história do jogo.

Desse modo, conclui-se que aplicar essas características na concepção de um jogo facilita o desenvolvimento e tende a tornar o jogo mais atrativo e com boa jogabilidade.

\section{REFERÊNCIAS}

[1] BRACKMANN, Christian. Desenvolvimento do Pensamento Computacional Através de Atividades Desplugadas na Educação Básica. 2017. Universidade Federal do Rio Grande do Sul (UFRGS), Porto Alegre, RS, Brasil, 2017. Disponível em: http://hdl.handle.net/10183/172208.

[2] MATTOS, M. M. et al. Uma pesquisa-ação sobre o desenvolvimento do pensamento computacional com crianças. In: VII Congresso Brasileiro de Informática na Educação (CBIE), Anais do XXIV Workshop de Informática na Escola (WIE), 2018, p. 421-429.

[3] ADAMS, Ernest; ROLLINGS, Andrew. Andrew Rollings and Ernest Adams on Game Desig. New Riders, 2003.

[4] ADAMS, Ernest. The High Concept Document. Välkommen till KTH. 2008

[5] CLAYPOOL, Mark; MORIARTY, Brian. The Game Development Process. 2010. Disonível em: <https://web.cs.wpi.edu/ imgd1001/a10/>.

\footnotetext{
${ }^{1}$ Disponível em: www.furb.br/ldtt/arquivos/projeto/furbot
} 